\title{
Evaluation of a carbon dioxide laser scalpel for disbudding Holstein calves: A pilot study
}

M. D. Kleinhenz, ${ }^{1 *} \odot$ A. K. Curtis, ${ }^{2} \odot$ M. M. Weeder, ${ }^{2}$ B. T. Johnson, ${ }^{3}$ D. Springfield, ${ }^{2} \odot$ M. Lou, ${ }^{2} \odot$ A. V. Viscardi, ${ }^{2}$ and J. F. Coetzee ${ }^{2}$ (1)

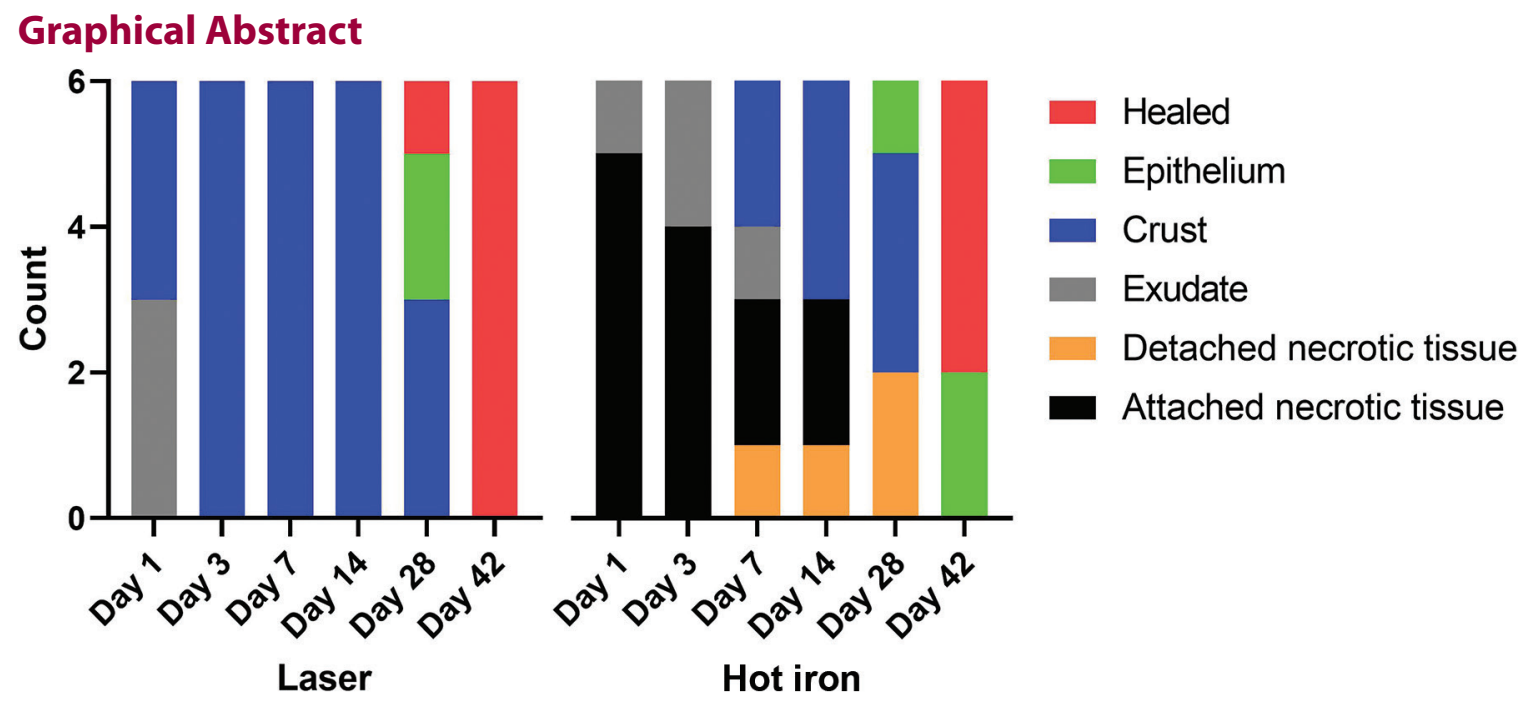

\section{Summary}

Cautery disbudding has been shown to be a painful husbandry procedure. Carbon dioxide $\left(\mathrm{CO}_{2}\right)$ surgical scalpels have been shown to decrease pain and inflammation in humans. This pilot study compared hot-iron cautery disbudding and a $\mathrm{CO}_{2}$ laser scalpel for disbudding. The use of a $\mathrm{CO}_{2}$ laser scalpel was not different from traditional hot-iron disbudding in pain measures.

\section{Highlights}

- Disbudding with a $\mathrm{CO}_{2}$ surgical scalpel was effective at removing horn tissue, and regrowth was not observed.

- All calves (6/6) disbudded with a $\mathrm{CO}_{2}$ laser were healed within $42 \mathrm{~d}$ of the procedure compared with 4 of 6 calves disbudded with a hot iron.

- Disbudding with a $\mathrm{CO}_{2}$ laser failed to improve mechanical nociception threshold tests compared with cautery disbudding.

${ }^{1}$ Department of Clinical Sciences, College of Veterinary Medicine, Kansas State University, Manhattan 66506, ${ }^{2}$ Department of Anatomy and Physiology, College of Veterinary Medicine, Kansas State University, Manhattan 66506, ${ }^{3}$ Department of Diagnostic Medicine/Pathobiology, College of Veterinary Medicine, Kansas State University, Manhattan 66506. *Corresponding author: mkleinhe@vet.k-state.edu. $\odot ~ 2021$, The Authors. Published by Elsevier Inc. and Fass Inc. on behalf of the American Dairy Science Association ${ }^{\circledast}$. This is an open access article under the CC BY license (http://creativecommons.org/licenses/ by/4.0/). Received January 27, 2021. Accepted March 15, 2021. 


\title{
Evaluation of a carbon dioxide laser scalpel for disbudding Holstein calves: A pilot study
}

\author{
M. D. Kleinhenz, ${ }^{1 *} \odot$ A. K. Curtis, ${ }^{2} \odot$ M. M. Weeder, ${ }^{2}$ B. T. Johnson, ${ }^{3}$ D. Springfield, ${ }^{2} \odot$ M. Lou, ${ }^{2} \odot$ \\ A. V. Viscardi, ${ }^{2}$ and J. F. Coetzee ${ }^{2} \odot$
}

\begin{abstract}
Cautery hot-iron disbudding is a painful routine husbandry practice performed on many dairy farms and calf rearing facilities. Refinements to eliminate or reduce the pain associated with disbudding are desired. Carbon dioxide $\left(\mathrm{CO}_{2}\right)$ laser scalpels cut and ablate tissue using high-power light energy. The objective of this study was to test the utility of a $\mathrm{CO}_{2}$ laser scalpel in bovine disbudding and to compare healing and pain measures with those of cautery hot-iron disbudding. Twelve Holstein bull calves (6-39 d of age) were enrolled in the study. Calves were randomly assigned into groups that were disbudded with a $\mathrm{CO}_{2}$ laser scalpel $(\mathrm{n}=6)$ or cautery hot iron $(\mathrm{n}=6)$. Calves were sedated with xylazine for the procedure and were given oral meloxicam and a local anesthetic block for analgesia. Outcome measures were maximum surface temperature by infrared thermography, mechanical nociception threshold (MNT) tests, and digital images for wound healing. The infrared thermography and MNT measures were collected before disbudding and out to $72 \mathrm{~h}$ postprocedure. Images for wound healing were collected before disbudding and at 6, 24, and $72 \mathrm{~h}$ and 7, 14, 28, and $42 \mathrm{~d}$ postdisbudding. Overall maximum surface temperatures were not different between groups $\left(35.3 \pm 0.3^{\circ} \mathrm{C}\right.$ vs. $36.0 \pm 0.3^{\circ} \mathrm{C}$ for laser and hot iron, respectively). No differences in overall MNT measures were noted between the laser calves $(2.28 \pm 0.19)$ and the hot-iron calves $(2.42 \pm 0.19 \mathrm{~kg}$ of force). All 6 calves in the laser group were completely healed by d 42, whereas only 4 out of 6 hot-iron calves were fully healed. These results suggest that disbudding calves using a $\mathrm{CO}_{2}$ laser scalpel may be painful based on the outcomes measured. Further research that focuses on pain associated with time points beyond those used in this study and that performs the procedure in unsedated calves is needed to fully evaluate its utility.
\end{abstract}

D isbudding is a common husbandry practice that occurs on the majority of dairy farms and calf rearing facilities. Often, disbudding is performed using a hot-iron dehorner, causing thermal damage to the horn tissue and ultimately death of the horn-forming epithelial cells. Cautery disbudding has been shown to cause pain and distress (Stafford and Mellor, 2005). Thus, less-painful disbudding alternatives have been investigated and are warranted (Hempstead et al., 2018; Sutherland et al., 2019). One downside to many alternatives is incomplete destruction of the horn tissue, which leads to formation of horn regrowth or scurs (Sutherland et al., 2019).

Carbon dioxide $\left(\mathrm{CO}_{2}\right)$ laser scalpels have been widely used for surgical procedures in human and veterinary medicine. They emit a colorless infrared light at a specific wavelength $(10,600 \mathrm{~nm})$, which is absorbed by intracellular water and causes tissue cells to ablate or vaporize (Mison et al., 2003). Carbon dioxide lasers allow for clean, precise incisions to be made on the skin and takes no more time than using a standard scalpel. Additionally, $\mathrm{CO}_{2}$ laser scalpels have been shown to significantly reduce pain and swelling in human patients who have undergone the same surgical procedure using a conventional metal scalpel (Tuncer et al., 2010; López-Jornet and Camacho-Alonso, 2013). The use of a $\mathrm{CO}_{2}$ laser for routine on-farm procedures has been studied. Recently, a $\mathrm{CO}_{2}$ scalpel was used for castrating male piglets, but no differences in wound healing were seen (Viscardi et al., 2020). There is potential for the $\mathrm{CO}_{2}$ laser to improve the welfare of calves undergoing disbudding by reducing pain and improving wound healing compared with hot-iron disbudding. The objective of this study was to describe disbudding using a $\mathrm{CO}_{2}$ laser scalpel and compare it with cautery hot-iron disbudding.

This work was approved by the Institutional Animal Care and Use Committee at Kansas State University (log no. 4443). Twelve male Holstein calves, 6 to $39 \mathrm{~d}$ of age (mean: $27 \mathrm{~d}$ ) and weighing 31 to $51 \mathrm{~kg}$ (mean: $43.5 \mathrm{~kg}$ ), were enrolled. Calves were individually housed in outdoor hutches with straw bedding. Calves were fed whole pasteurized milk twice daily and had grain and water available at all times. Calves were blocked by age and randomly assigned to 1 of 2 treatments groups: (1) disbudding with a $\mathrm{CO}_{2}$ laser scalpel ( $\mathrm{n}=6$; VetScalpel, Aesulight LLC) or (2) disbudding with a cautery hot iron $(\mathrm{n}=6$; Express Inline, The Coburn Co. Inc.). Randomization was completed using a random number generator (Excel, Microsoft Corp.).

All calves were sedated and received analgesia for the disbudding procedure. Before sedation, all calves were administered meloxicam (Zydus Pharmaceuticals Inc.) at $1 \mathrm{mg} / \mathrm{kg}$ by mouth. Calves were sedated with xylazine (XylaMed, VetOne) at $0.15 \mathrm{mg} /$ $\mathrm{kg}$ i.m. $15 \mathrm{~min}$ before the disbudding procedure. Once sedated, a cornual nerve block was provided using 2\% lidocaine (VetOne; $5 \mathrm{~mL} / \mathrm{side}$ ) as described by Stock et al. (2015) $5 \mathrm{~min}$ before the disbudding procedure.

For the laser disbudding procedure, sedated calves were places in lateral recumbency on a cart with their head restrained with a

\footnotetext{
'Department of Clinical Sciences, College of Veterinary Medicine, Kansas State University, Manhattan 66506, ${ }^{2}$ Department of Anatomy and Physiology, College of Veterinary Medicine, Kansas State University, Manhattan 66506, ${ }^{3}$ Department of Diagnostic Medicine/Pathobiology, College of Veterinary Medicine, Kansas State University, Manhattan 66506. *Corresponding author: mkleinhe@vet.k-state.edu. $\odot ~ 2021$, The Authors. Published by Elsevier Inc. and Fass Inc. on behalf of the American Dairy Science Association ${ }^{\circledast}$. This is an open access article under the CC BY license (http://creativecommons.org/licenses/ by/4.0/). Received January 27, 2021. Accepted March 15, 2021.
} 
rope halter. The hair over the horn buds was clipped using an electric clipper. The $\mathrm{CO}_{2}$ laser scalpel was set to $30 \mathrm{~W}$ of power on a continuous pattern with a focal point of $0.4 \mathrm{~mm}$. Using the laser, a circular incision was made around the horn tissue; then, the horn tissue was undermined by cutting the tissue away from the skull. Hemostasis was applied using hemostats if needed. The laser was calibrated before starting the study, after the third calf, and after the last (sixth) calf. The calibration results were 72.2, 78.1, and 75.1\%, indicating that the laser operated normally.

For cautery hot-iron disbudding, sedated calves were placed in lateral recumbency on the ground. The hair over the horn buds was clipped using an electric clipper. The dehorner was applied to each horn bud for $10 \mathrm{~s}$, and the horn tissue was removed. The dehorner had a cutting diameter of $19 \mathrm{~mm}$. At the completion of the disbudding procedures all calves received atipamezole (Antisedan, Zoetis Inc.) at $0.04 \mathrm{mg} / \mathrm{kg}$ i.m. to reverse the sedation.

Outcome variables were collected from least to most invasive as determined by the investigators. Outcome variables collected (in order) were digital photographs of the disbudding site, infrared thermography (IRT) of the disbudding site, and mechanical nociception (MNT).

Digital photographs of the disbudding area were taken using a hand-held digital camera (Olympus Stylus, Olympus Corp.) to monitor wound healing progression applying methods adapted from Adcock and Tucker (2018). Photographs were taken before disbudding and at 6,24 , and $72 \mathrm{~h}$ and $7,14,28$, and $42 \mathrm{~d}$ postdisbudding. To obtain images, calves were tightly restrained using a rope halter, and a photo of each horn was taken at a distance of 0.25 $\mathrm{m}$ from the disbudding site. Table 1 lists the tissue types used to describe wound healing progression.

Infrared thermographic images of the left horn bud were obtained for maximum surface temperatures using a commercial thermography camera (Fluke TiX580, Fluke Corp.) using methods adapted from Kleinhenz et al. (2017). Calves were restrained using a rope halter, and the left lateral aspect of the head was obtained. The camera was held approximately $0.5 \mathrm{~m}$ from the calf's head at a $45^{\circ}$ angle. Images were obtained before disbudding and at 1, 2, 4, $6,24,48$, and $72 \mathrm{~h}$ postdisbudding. To ensure consistent imaging, all images were obtained by the same investigator. Images were analyzed using commercial software (SmartView version 4.3, Fluke Thermography), and the maximum surface temperature of the disbudding area was recorded for statistical analysis.

The MNT was obtained before disbudding (baseline) and at 4, $6,24,48$, and $72 \mathrm{~h}$ postdisbudding using methods described by Kleinhenz et al. (2017). For MNT determination, calves were tightly restrained with a rope halter, and a blindfold was placed over their eyes to prevent responses due to visual cues. A hand-held algometer (Wagner Instruments) was used to determine MNT by applying force perpendicular to the skull at approximately $1 \mathrm{~kg}$ of force $(\mathbf{k g f}) / \mathrm{s}$. All MNT values were obtained by a single investigator. Sites tested for MNT were 2 locations (lateral and caudal) adjacent to the disbudding site around each horn and a third control location on the frontal bone between the eyes. Locations were tested 3 times in sequential order, and the value was averaged for statistical analysis.

Response outcomes included in the analysis were maximum surface temperature taken by IRT and MNT measures. Statistical analysis was performed using computer software (JMP 15.0, SAS Institute Inc.). Responses were analyzed using a mixed model with calf as the experimental unit. Treatment was assigned as the random effect, and time and treatment $\times$ time interaction were considered fixed effects. Post hoc tests were conducted using Tukey-Kramer adjustment. Statistical significance was set at $P<0.05$ a priori.

Representative wound healing images and progression of wound healing by time point are presented in Figure 1 . At $6 \mathrm{~h}$ postdisbudding, exudate was observed for calves in the laser groups and burned tissue was observed for calves in the hot-iron group. All calves in the laser group were completely healed on $\mathrm{d} 42$, and no evidence of regrowth (scur formation) was noted. Four of the hot-iron calves were completely healed, and the remaining 2 had epithelium covering the disbudding site.

No differences were found in the maximum or minimum temperature of the disbudding sites between treatment groups. There was a tendency $(P=0.10)$ for differences in overall mean maximum temperature by IRT (laser calves: $35.3^{\circ} \mathrm{C}, 95 \% \mathrm{CI}$ : $34.7-36.0^{\circ} \mathrm{C}$; hot-iron calves: $36.0^{\circ} \mathrm{C}, 95 \% \mathrm{CI}$ : $35.4-36.7^{\circ} \mathrm{C}$ ). No treatment $\times$ time interaction was observed for the maximum IRT temperatures $(P=0.57)$. A time effect was observed $(P=0.01)$. At $1 \mathrm{~h}$ postdisbudding, the mean maximum temperature was $34.6^{\circ} \mathrm{C}$ $\left(95 \% \mathrm{CI}: 33.1-36.0^{\circ} \mathrm{C}\right)$ for the laser calves and $36.9^{\circ} \mathrm{C}(95 \% \mathrm{CI}$ : $35.5-38.4^{\circ} \mathrm{C}$ ) for the hot-iron calves. Peak mean maximum temperaturewas observed at $4 \mathrm{~h}$. The observed temperatures at $4 \mathrm{~h}$ postdisbudding were $37.0^{\circ} \mathrm{C}\left(95 \% \mathrm{CI}: 35.6-38.5^{\circ} \mathrm{C}\right)$ and $37.5^{\circ} \mathrm{C}$ ( $95 \% \mathrm{CI}: 36.0-38.9^{\circ} \mathrm{C}$ ) for the laser and hot-iron groups, respectively.

No treatment effects were observed for the MNT measures $(P=$ $0.59)$. A time effect did result $(P>0.0001)$, but no treatment $\times$ time interaction was found $(P=0.20$; Figure 2$)$. Mean baseline MNT measures for the hot-iron and laser groups were $5.29 \mathrm{kgf}(95 \% \mathrm{CI}$ : $4.72-5.85 \mathrm{kgf})$ and $4.73 \mathrm{kgf}(95 \% \mathrm{CI}: 4.17-5.30 \mathrm{kgf})$, respectively.

Table 1. Descriptions used to classify wound healing progression (adapted from Adcock and Tucker, 2018)

\begin{tabular}{ll}
\hline Tissue & Description \\
\hline Burned tissue & Hairless areas outside the copper ring \\
Attached necrotic tissue & Copper edges attached to the skull \\
Detached necrotic tissue & Edges of the copper ring started to separate from the scalp \\
Exudate & Fresh blood or serum (clear fluid); moist or freshly dried \\
Granulation & Dark pink to light red bumpy tissue \\
Crust & Dried exudate covering dehorning site \\
Epithelium & Layer of translucent skin is present; no hair regrowth present \\
Healed & Complete epithelialization with hair regrowth \\
\hline
\end{tabular}




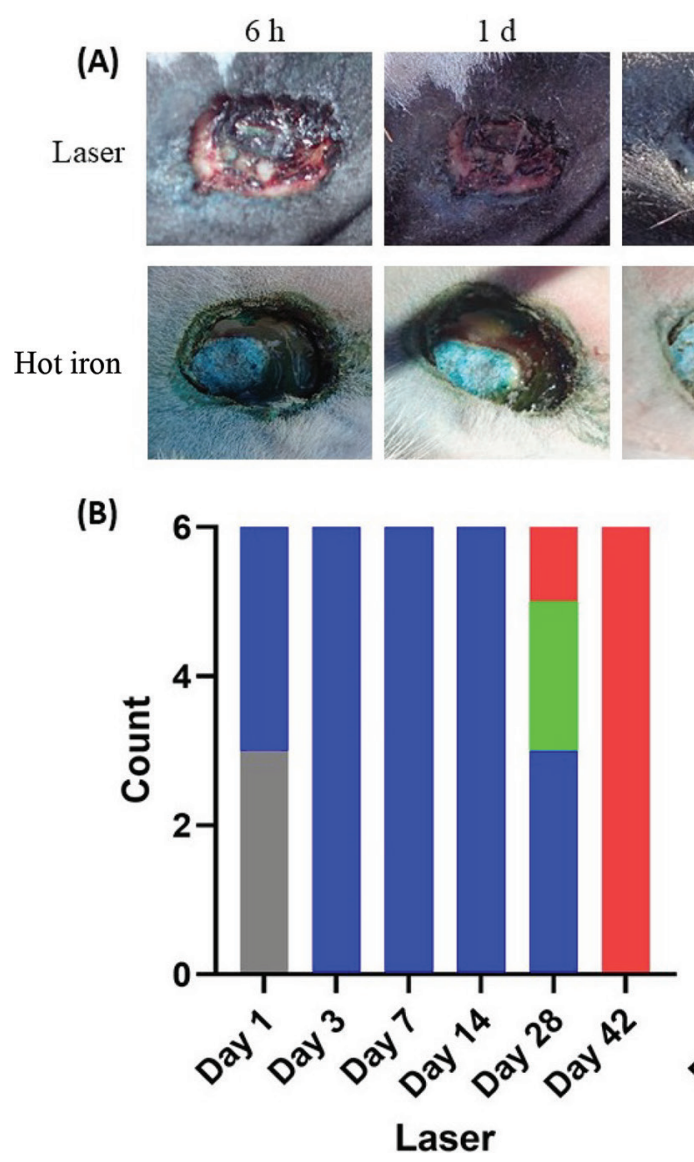

$3 \mathrm{~d}$
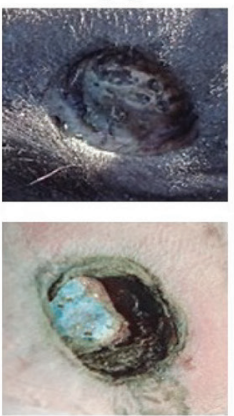

$7 \mathrm{~d}$
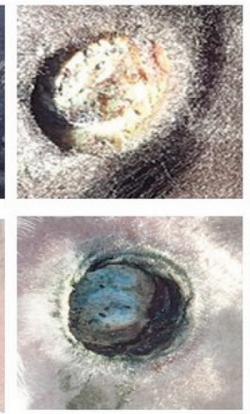

$14 \mathrm{~d}$
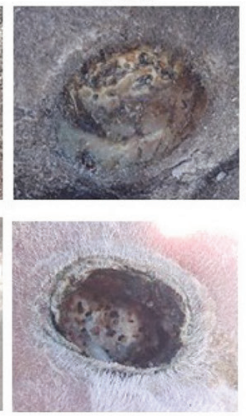

$28 \mathrm{~d}$
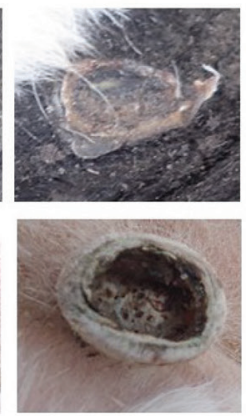

$42 \mathrm{~d}$

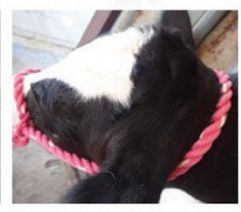

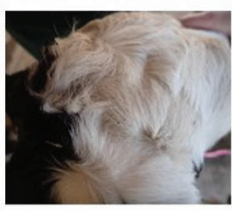

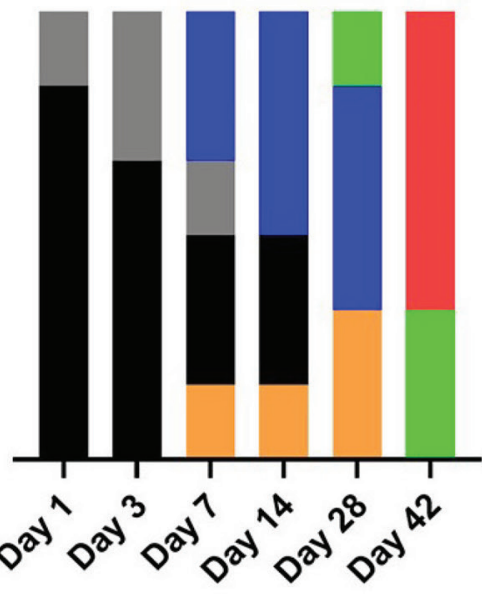

Hot iron

Figure 1. (A) Representative images of disbudding sites at $6 \mathrm{~h}$ and $1,3,7,14,28$, and $42 \mathrm{~d}$ for calves disbudded with either $\mathrm{CO}_{2}$ surgical scalpel (laser; top row) or hot-iron cautery dehorner (bottom row). (B) Individual calf observations of healing progression by time point for calves disbudded with either $\mathrm{CO}_{2}$ surgical scalpel (laser) or hot-iron cautery dehorner.

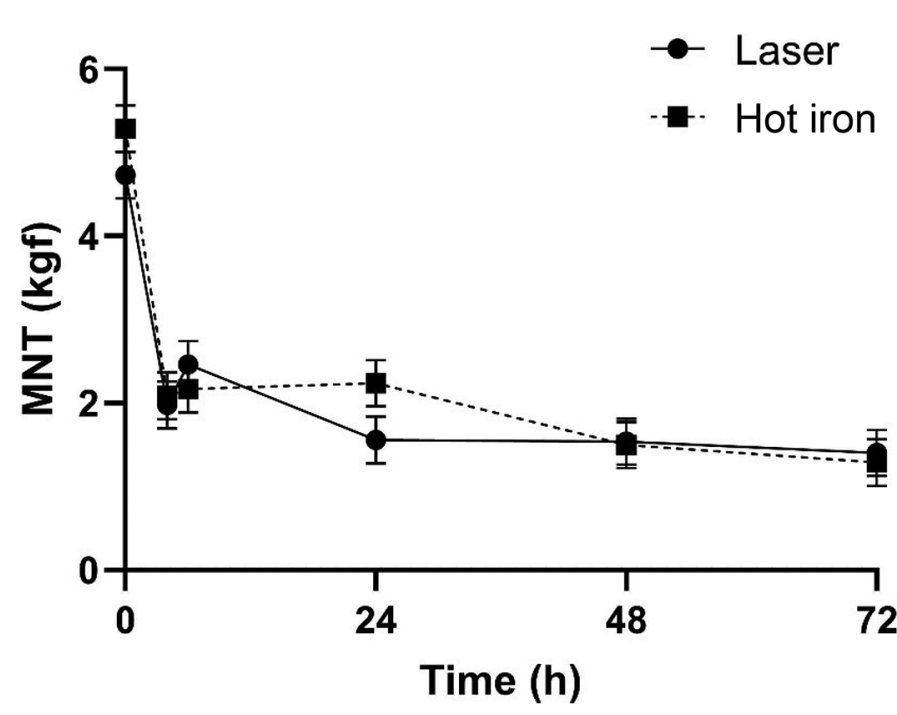

Figure 2. Mean $( \pm S E)$ mechanical nociception threshold (MNT) measures for calves disbudded by either cautery hot iron $(n=6)$ or $\mathrm{CO}_{2}$ surgical scalpel (laser, $\mathrm{n}=6$ ). $\mathrm{kgf}=$ kilograms of force.
The lowest measured MNT values were observed at $72 \mathrm{~h}$ for both treatment groups. At $72 \mathrm{~h}$, the mean MNT measures for the hotiron and laser groups were $1.29 \mathrm{kgf}(95 \% \mathrm{CI}: 0.72-1.85 \mathrm{kgf})$ and $1.40 \mathrm{kgf}$ (95\% CI: $0.83-1.97 \mathrm{kgf})$, respectively.

At the control MNT location, no treatment effects $(P=0.34)$ or treatment $\times$ time interactions $(P=0.60)$ were found. A time effect was seen $(P=0.04)$, as the lowest MNT measures were observed at $4 \mathrm{~h}$ postdisbudding for the hot-iron (5.54 kgf; 95\% CI: 4.55-6.53 kgf) and laser (5.84 kgf; 95\% CI: 4.85-6.83 kgf) groups. The highest MNT measures were seen at baseline for the hot-iron group (7.26 kgf; 95\% CI: $6.27-8.25 \mathrm{kgf}$ ). Alternatively, for the laser group, the highest MNT measures were seen at $72 \mathrm{~h}$ postdisbudding (6.45 kgf; 95\% CI: 5.46-7.44 kgf).

This project reports the first use of a $\mathrm{CO}_{2}$ laser for disbudding in cattle. Blinding was not possible due to the differences in disbudding type and study size and the visual differences following the disbudding procedure. Calves in both treatment groups were sedated with xylazine before the disbudding procedure. This was due to unknown factors of the $\mathrm{CO}_{2}$ laser disbudding procedurenamely, the length of the procedure and unforeseen complications. The length of the laser disbudding procedure was less than $30 \mathrm{~s} /$ horn, but time comparisons with the traditional hot-iron procedure were not made. The only complication encountered with the laser 
disbudding was hemorrhage from the cornual artery. Hemostasis of the cornual artery was easily achieved with hemostats and additional ablation with the $\mathrm{CO}_{2}$ laser.

The disbudding wounds in both groups healed faster than those reported by Adcock and Tucker (2018). Factors contributing to this finding include different dehorner types used as well as different operators. The dehorner used for the hot-iron group had a cutting diameter of $19 \mathrm{~mm}$ and a cutting edge of $1 \mathrm{~mm}$. The $\mathrm{CO}_{2}$ laser was set to $0.4-\mathrm{mm}$ cutting width. Although the diameter of horn tissue removed was not measured, the laser incision was made at the horn-hair junction. A benefit of the $\mathrm{CO}_{2}$ laser was that the amount of tissue removed was dependent on the diameter of the horn. A perceived risk of the laser procedure was incomplete removal or killing of the horn epithelium, leading to scur formation. This failure of disbudding was not observed in this study.

The calves used in the present study were purchased specifically for an unrelated vaccine project. Collection of IRT and MNT data beyond the 72-h time point was not possible due to the timing of the disbudding procedure and vaccination dates. This limited the follow-up of data collection to $72 \mathrm{~h}$ for IRT and MNT. Time points for obtaining digital images to describe wound progression were kept to the sampling dates of the subsequent vaccine study.

Calves in the laser group tended to have lower maximum surface temperatures of the disbudding site as measured by IRT. This may be related to decreased inflammation at the disbudding sites compared with hot-iron disbudding. The observed time effect with a peak temperature seen at $4 \mathrm{~h}$ postdisbudding in both groups is likely due to the time of day these images were obtained (afternoon) and may have been influenced by ambient temperatures (Church et al., 2014). Surface temperatures taken by IRT following disbudding in cattle for the time period reported in this study ( 72 h) are deficient in the literature. In goats, the surface temperature was elevated compared with sham controls following cautery and caustic paste disbudding (Hempstead et al., 2018). Adcock et al. (2019) reports maximum surface temperatures, but the first time point following disbudding was $7 \mathrm{~d}$ postprocedure.

No differences were observed between treatments on MNT measures following disbudding. This suggests that disbudding by laser or hot iron causes a similar amount of pain. In this pilot study, calves were followed for only $72 \mathrm{~h}$ following disbudding due to logistics and study timing. Additionally, time effects were seen at the control MNT site. The lowest MNT measure for both treatment groups at the control site was at $72 \mathrm{~h}$ disbudding, further supporting that both procedures were painful.

Following retrospective evaluation, it is our opinion that the $\mathrm{CO}_{2}$ laser procedure could be completed in an unsedated calf with a local anesthetic block and calf restraint device. Future research using $\mathrm{CO}_{2}$ laser scalpels for disbudding should focus on calf behavior when disbudded without sedation and on obtaining pain measures at later time points. The latter need is important because recent literature has shown that calves are sensitive to disbudding beyond $11 \mathrm{~d}$ postprocedure (Adcock et al., 2020). The observed differences in wound healing progression, with the $\mathrm{CO}_{2}$ laser calves healing faster, supports the need for future work following pain behaviors and pain measures out to complete healing. This alternative method shows promise, but a more robust study including a control group, physiologic indicators of pain, and extended measurements of outcomes is needed.

\section{References}

Adcock, S. J. J., D. M. Cruz, and C. B. Tucker. 2020. Behavioral changes in calves 11 days after cautery disbudding: Effect of local anesthesia. J. Dairy Sci. 103:8518-8525. https://doi.org/10.3168/jds.2020-18337.

Adcock, S. J. J., and C. B. Tucker. 2018. The effect of disbudding age on healing and pain sensitivity in dairy calves. J. Dairy Sci. 101:10361-10373. https://doi.org/10.3168/jds.2018-14987.

Adcock, S. J. J., S. K. Vieira, L. Alvarez, and C. B. Tucker. 2019. Iron and laterality effects on healing of cautery disbudding wounds in dairy calves. J. Dairy Sci. 102:10163-10172. https://doi.org/10.3168/jds.2018-16121.

Church, J. S., P. R. Hegadoren, M. J. Paetkau, C. C. Miller, G. Regev-Shoshani, A. L. Schaefer, and K. S. Schwartzkopf-Genswein. 2014. Influence of environmental factors on infrared eye temperature measurements in cattle. Res. Vet. Sci. 96:220-226. https://doi.org/10.1016/j.rvsc.2013.11.006.

Hempstead, M. N., J. R. Waas, M. Stewart, V. M. Cave, and M. A. Sutherland. 2018. Evaluation of alternatives to cautery disbudding of dairy goat kids using physiological measures of immediate and longer-term pain. J. Dairy Sci. 101:5374-5387. https://doi.org/10.3168/jds.2017-13814.

Kleinhenz, M. D., N. K. Van Engen, P. J. Gorden, J. Ji, P. Walsh, and J. F. Coetzee. 2017. Effects of transdermal flunixin meglumine on pain biomarkers at dehorning in calves. J. Anim. Sci. 95:1993-2000. https://doi.org/10 $.2527 /$ jas.2016.1138.

López-Jornet, P., and F. Camacho-Alonso. 2013. Comparison of pain and swelling after removal of oral leukoplakia with $\mathrm{CO}_{2}$ laser and cold knife: A randomized clinical trial. Med. Oral Patol. Oral Cir. Bucal 18:e38-e44. https://doi.org/10.4317/medoral.17960.

Mison, M. B., B. Steficek, M. Lavagnino, B. D. Teunissen, J. G. Hauptman, and R. Walshaw. 2003. Comparison of the effects of the $\mathrm{CO}_{2}$ surgical laser and conventional surgical techniques on healing and wound tensile strength of skin flaps in the dog. Vet. Surg. 32:153-160. https://doi.org/10.1111/j.1532 -950X.2003.00153.x.

Stafford, K. J., and D. J. Mellor. 2005. Dehorning and disbudding distress and its alleviation in calves. Vet. J. 169:337-349. https://doi.org/10.1016/j.tvjl .2004.02.005.

Stock, M. L., S. T. Millman, L. A. Barth, N. K. Van Engen, W. H. Hsu, C. Wang, R. Gehring, R. L. Parsons, and J. F. Coetzee. 2015. The effects of firocoxib on cautery disbudding pain and stress responses in preweaned dairy calves. J. Dairy Sci. 98:6058-6069. https://doi.org/10.3168/jds.2014-8877.

Sutherland, M. A., F. J. Huddart, and M. Stewart. 2019. Short communication: Evaluation of the efficacy of novel disbudding methods for dairy calves. J. Dairy Sci. 102:666-671. https://doi.org/10.3168/jds.2018-15230.

Tuncer, I., C. Ozçakir-Tomruk, K. Sencift, and S. Cöloğlu. 2010. Comparison of conventional surgery and $\mathrm{CO}_{2}$ laser on intraoral soft tissue pathologies and evaluation of the collateral thermal damage. Photomed. Laser Surg. 28:75-79. https://doi.org/10.1089/pho.2008.2353.

Viscardi, A. V., C. A. Cull, M. D. Kleinhenz, S. Montgomery, A. Curtis, K. Lechtenberg, and J. F. Coetzee. 2020. Evaluating the utility of a $\mathrm{CO}_{2}$ surgical laser for piglet castration to reduce pain and improve wound healing: A pilot study. J. Anim. Sci. 98:skaa320. https://doi.org/10.1093/jas/skaa320.

\section{Notes}

M. D. Kleinhenz (D) https://orcid.org/0000-0001-9453-3657

A. K. Curtis (D) https://orcid.org/0000-0002-3087-2841

D. Springfield (10 https://orcid.org/0000-0003-0556-2283

M. Lou (1) https://orcid.org/0000-0002-8962-0948

J. F. Coetzee (ํ) https://orcid.org/0000-0003-1802-3991

This project was supported by Agriculture and Food Research Initiative Competitive Grant No. 2020-67015-31540 from the USDA National Institute of Food and Agriculture (Washington, DC). J. F. Coetzee, M. D. Kleinhenz, and A. V. Viscardi were supported by Agriculture and Food Research Initiative Competitive Grant No. 2017-67015-27124, 2020-67030-31479, 2020-6701531540, 2020-67015-31546, and 2021-67015-34084 from the USDA National Institute of Food and Agriculture.

The authors thank Dannelle Kopp (Kansas State University, Manhattan) for her assistance with sample collection and the Kansas State University Dairy Facility (Manhattan) for providing animal care and housing.

The authors have not stated any conflicts of interest. 